\title{
EXTENSÃO UNIVERSITÁRIA "AMIGOS DO PEITO": UMA FRENTE DE COMBATE AO CÂNCER DE MAMA
}

\author{
Leyde Jenifer Dias Uchôal, Ana Maria Correia Alencarl, Bárbara Torquato Alves ${ }^{1}$, \\ Brenda Lacerda da Silval, Bruna Figueiredo Medeiros ${ }^{1}$, \\ Antonio Marlos Duarte de Melo', Ricardo Souto Quidute ${ }^{2}$
}

Introdução: Preconceito, negligência e desconhecimento são apenas alguns dos fatores que giram em torno da problemática social que é o câncer de mama, neoplasia mais comum entre o sexo feminino cuja elevada mortalidade por ela conferida faz com que os profissionais de saúde devam estar alerta e cientes de como é imprescindível a orientação da população quanto aos benefícios de não menosprezar a doença e, as vantagens de um diagnóstico precoce para uma boa evolução após estabelecida a patologia. Objetivo: Incentivar o diagnóstico precoce do CA de mama em mulheres participantes das atividades e gerar agentes multiplicadores das informações sobre as neoplasias mamárias na região do Cariri. Método: O projeto de extensão consiste na atuação de alunos da Faculdade de Medicina Estácio do Juazeiro do Norte, previamente capacitados, que realizaram palestras, oficinas, dinâmicas de grupo e entrevistas com as famílias da comunidade, sob a supervisão do professor assistente. As ações são desenvolvidas em Unidades Básicas de Saúde (UBS) e em outros lugares públicos, onde o públicoalvo possa ser encontrado e abordado, dentro dos municípios de Juazeiro do Norte, Crato e Barbalha. São realizadas atividades educativas, rodas de conversas a respeito do conhecimento das mesmas sobre o tema, os exames dedicados ao diagnóstico precoce e as patologias mamária, benignas e malignas. Resultados: Tendo em vista a necessidade de atenção à comunidade, a Liga Acadêmica de Oncologia da Faculdade de Medicina Estácio do Juazeiro do Norte (FMJ) idealizou o projeto de extensão universitária "Amigos do Peito", no intuito de informar e conscientizar a população, em especial mulheres, sobre o câncer de mama. Os encontros com a comunidade têm elucidado dúvidas e norteado decisões e ações sobre prevenção e detecção precoce. Por relatos das mulheres assistidas pelo projeto é possível ver o empoderamento que a informação e a educação em saúde promovem à sociedade. Conclusão: Para combater o câncer de mama, uma equipe de alunos tem feito um significativo empenho através de palestras, oficinas, dinâmicas de grupo e entrevistas com as famílias em comunidades, seja em postos de saúde seja no ambulatório da FMJ, com o objetivo de instruir mulheres sobre tão temível patologia. Há um esforço contínuo de melhorar e alcançar os objetivos deste projeto, focando na inclusão social e ampliando seu alcance sobre a sociedade.

Palavras-chave: Câncer da mama. Educação em saúde. Diagnóstico precoce.

\footnotetext{
${ }^{1}$ Discente do curso de Medicina pela Faculdade de Medicina Estácio de Juazeiro do Norte

${ }^{2}$ Docente da Faculdade de Medicina Estácio de Juazeiro do Norte - FMJ, médico Mastologista.

Autor Correspondente: leydejenifer@gmail.com.
}

33 Id on Line Rev. Mult. Psic. V.12, N. 40. 2018 - ISSN 1981-1179 EDIÇÃO ESPECIAL: I CURSO DE ONCOLOGIA DO CARIRI / II JORNADA DE PESQUISA QUANTI-QUALITATIVA EM ONCOLOGIA. JUAZEIRO DO NORTE, 05 A 10 DE MARÇO DE 2018. Edição eletrônica em http://idonline.emnuvens.com.br/id 